PRZEGLĄD NAUK HISTORYCZNYCH 2018, R. XVII, NR 1

http://dx.doi.org/10.18778/1644-857X.17.01.04

Aneta Pawlowska

UNIWERSYTET ŁÓDZKI

Hanna Rubinkowska-Aniot

UNIWERSYTET WARSZAWSKI

\title{
Źródla ikonograficzne do badań afrykanistycznych. Zarys problematyki
}

Streszczenie. Celem artykułu jest rozważenie, czy możliwe jest wsparcie badań nad historią i kulturą Afryki Subsaharyjskiej dzięki analizie źródeł ikonograficznych związanych $z$ tym kontynentem. Najistotniejszym powodem takiego postępowania jest zasadniczy brak dokumentów pisanych w tradycyjnej kulturze afrykańskiej. Równie ważnym elementem analiz zawartych w artykule jest zwrócenie uwagi na zróżnicowanie przedstawień wizualnych pochodzacych $z$ tego obszaru geograficznego. Kolejną przesłanką do zagłębienia się w ikonografię kontynentu może być próba poszerzenia odbioru kultury Afryki, zwłaszcza zaś próba porzucenia europocentrycznych sposobów opisywania świata.

Słowa kluczowe: Afryka, kultura, ikonografia, sztuki wizualne, historia.

\section{Wprowadzenie}

I

konografia to nauka pomocnicza historii sztuki powstała w wieku XIX, zajmujaca się treścią lub znaczeniem dzieła sztuki, rozpoznawaniem i klasyfikacja tematów dzieł sztuki, badaniem ich występowania, powstawaniem wariantów pewnych przedstawień i motywów, a także odczytywaniem treści symboli, personifikacji, atrybutów itp. Pomaga w datowaniu dzieł sztuki lub w ustaleniu

\footnotetext{
*Wydział Filozoficzno-Historyczny, Katedra Historii Sztuki, e-mail: aneta.pawlowska@uni.lodz.pl.

${ }^{* *}$ Wydział Orientalistyczny, Katedra Języków i Kultur Afryki, e-mail: hrubinkowska@yahoo.com.
} 
ich autentyczności. Według klasycznej pozycji Erwina Panofsky’ego (1892-1968) z zakresu analizy historii sztuki ikonografia to „dziedzina historii sztuki [, która - przyp. A.P., H.R.-A.] zajmuje się treścią lub znaczeniem dzieła sztuki, pojętym jako przeciwstawienie formy" ${ }^{1}$. Analiza ikonograficzna w tym rozumieniu opiera się na znajomości źródeł literackich, tj. specyficznych pojęć i tematów oraz znajomości historii stylu i pewnych „typów przedstawień”, które pojawiają się na przestrzeni wieków i za pomocą których były wyrażane obrazy rzeczy, zdarzeń, ale też tematy i pojęcia. Jednak wraz $z$ rozwojem dziedziny nie tylko metodę Panofsky'ego poddano krytyce, lecz także wskazano na inne możliwości wykorzystania obrazu jako źródła, w tym $z$ uwzględnieniem badań nad historią społeczną. Badania nad ikonografią afrykańska i poświęcona Afryce również wykraczają poza podejście Panofsky'ego. Chociażby dlatego, że w Afryce teksty pisane sa nieliczne (w Afryce Subsaharyjskiej ${ }^{2}$ sztuka pisma nie była powszechnie stosowana), a różnice kulturowe między światem Zachodu, w którym ukute zostały zasady „czytania obrazów”, a Afryką - zasadnicze. Zarówno wiedza, jaka mamy, jak i nasza perspektywa badawcza zostały ukształtowane przez krag kulturowy, w którym żyjemy. Pojawia się zatem pytanie, czy jako wywodzacy się $z$ cywilizacji Starego Kontynentu jesteśmy w stanie prawidłowo identyfikować motywy, alegorie i symbole osadzone w afrykańskim kontekście kulturowym?

Celem artykułu jest ukazanie problematyki związanej $z$ wykorzystaniem ikonografii $\mathrm{w}$ badaniach afrykanistycznych. W tekście zaproponowano dyskusję nad możliwościami interpretacji afrykańskich wytworów kultury materialnej i rozszerzenie znaczenia ikonografii jako istotnej części bazy źródłowej niezbędnej do badania historii, kultur i zagadnień społecznych w Afryce. Wielu historyków i antropologów korzysta $z$ analizy przedstawień wizualnych $\mathrm{w}$ badaniach afrykanistycznych. Wśród polskich prac historycznych wskazać można chociażby dorobek Michała Tymowskiego ${ }^{3}$. s. 11 .

${ }^{1}$ E. Panofsky, Studia z historii sztuki, oprac. J. Białostocki, Warszawa 1971,

2 Afryka Subsaharyjska to tereny afrykańskie położone na południe od Sahary, czyli południe Sawanny i basen Konga, Międzyrzecze, wyżyny południa kontynentu. Por. Historia Afryki do początku XIX wieku, red. M. Tymowski, Wrocław 1996, s. VIII-IX.

${ }^{3}$ Por. m.in. M. Tymowski, Europejczycy i Afrykanie: Wrajemne odkrycia i pierwsze kontakty, Toruń 2017 (seria: Monografie Fundacji na rzecz Nauki Polskiej). 
Jednak zdaniem autorek wielość zagadnień i złożoność problemu afrykańskiej ikonografii, a przede wszystkim zmieniający się kontekst jej funkcjonowania wymaga wskazania pułapek, które napotyka badacz korzystający ze źródeł wizualnych.

Pojęcie „afrykańska ikonografia” autorki rozumieja szeroko - jako badania nad obrazem w znaczeniu używanym przez Petera Burke'a ${ }^{4}$. Przy czym obraz ten utrwalony może być zarówno w sztukach plastycznych, wytworach rzemiosła, jak i w dokumentach wizualnych $-\mathrm{m}$.in. na fotografiach. Istotne w tym kontekście sa nie tylko źródła stricte afrykańskie, czyli wewnętrzne, tworzone przez Afrykanów, lecz także zewnętrzne, zatem te, które przedstawiały Afrykanów i Afrykę, ale były wynikiem twórczości przyjezdnych. Przykładem tego rodzaju źródeł są mapy Afryki. W niniejszym artykule jednakże rozważania dotyczą jedynie problemów związanych $z$ analiza afrykańskich, nie zewnętrznych, wytworów kultury materialnej. Autorki skupiaja się na obszarze położonym na południe od Sahary, chociaż w niektórych przypadkach przykłady $z$ północy kontynentu dobrze ilustruja przedstawiane tezy. Wynika to $z$ wielu kulturowych powiązań, które przez wieki funkcjonowały pomimo dziś rozdzielającej te tereny pustyni ${ }^{5}$. Celem tekstu jest też przedstawienie stosunkowo zróżnicowanych obiektów, których rola w kulturze i historii (zarówno w wymiarze mikro-, jak i makroregionów) Afryki jest istotna, a zarazem trudna do zrozumienia przez osoby $z$ innego kręgu kulturowego. Konteksty, w jakich funkcjonowały i funkcjonują wszystkie te obiekty, kształtowały się jako wynik procesów zachodzących w Afryce, niektóre $z$ nich dotyczyły tylko mieszkańców tego kontynentu i ich kultur, inne miały zasięg znacznie szerszy i obejmowały kontakty $z$ cywilizacjami pozaafrykańskimi. W podjętych rozważaniach istotny jest termin „sztuka afrykańska”. Większość języków afrykańskim, o ile nie wszystkie, nie zawierała słowa oznaczającego to samo co słowo „sztuka” w językach europejskich. Nieznane było pojęcie „sztuka” jako działalność skoncentrowana jedynie na twórczości artystycznej, w oderwaniu od jej zastosowania praktycznego, tj. w służbie religii, władzy bądź utrwalania relacji społecznych.

Przykładem funkcjonowania sztuki na potrzeby zarówno religii, jak i w kontekście społecznym są artefakty związane $z$ działalno-

${ }^{4}$ Por. P. Burke, Naoczność. Materiały wizualne jako świadectwa historyczne, Kraków 2012.

${ }^{5}$ Historia Afryki..., s. 442-444. 
ścią sekretnych stowarzyszeń ${ }^{6}$. Stowarzyszenia te, funkcjonujacce przede wszystkim w zachodniej Afryce, sa i były instytucjami niezbędnymi do określenia stosunków społecznych w wielu afrykańskich społecznościach. Sa to organizacje nieformalne, istnieją poza oficjalnym systemem politycznym oraz systemem pokrewieństwa klanowego. Gromadza przede wszystkim mężczyzn, rzadko kobie$t^{7}$. Niektóre ze stowarzyszeń sa jawne, choć ich ceremonie sa zastrzeżone tylko dla członków, inne działają w ukryciu, są tajne w ścisłym sensie. Część $z$ nich ma charakter ponadetniczny, tak jak w przypadku zwiazku Poro w Liberii i Sierra Leone. Ich członkowie są depozytariuszami plemiennych tradycji i mitów, a także wiedzy ${ }^{8}$. Tam, gdzie funkcjonuje kult przodków (np. w grupach etnicznych, w których działają związki Poro i Sande), członkowie związków sa pośrednikami w kontaktach ze zmarłymi ${ }^{9}$. W gestii stowarzyszeń leży także organizacja ceremonii zapewniających wspólnocie płodność i dobrobyt. Wiedza, która nie jest ogólnie dostępna, zapewnia członkom władzę, odgrywają też oni istotną rolę w wymiarze sprawiedliwości, przejmując zadania, które w świecie Zachodu wykonuje m.in. policja. Takie obowiązki (czyli strzeżenie społeczności przed antyspołecznymi zachowaniami jej członków) wypełnia Komo, jedno ze stowarzyszeń Bambarów w Mali. Członkowie tajnych związków w dużej mierze są odpowiedzialni za organizacje życia całych społeczności.

Jak zostało wspomniane, działalność stowarzyszeń związana jest też często $z$ kultem antenatów. W wielu kulturach afrykańskich rola przodków jest niezwykle istotna. Tak jest u Mossich,

${ }^{6}$ Badania nad tajnymi stowarzyszeniami prowadzone są od końca XIX w. (por. m.in. H.P. Fitzgerald Marriott, The Secret Societies of West Africa, „The Journal of the Anthropological Institute of Great Britain and Ireland" 1899, vol. XXIX, No. 1/2, s. 21-27). Od tego czasu pojawiało się sporo kontrowersji, np. w latach trzydziestych XX w. Evans-Pritchard głosił, że istnienie tajnych stowarzyszeń wśród Azande jest wymysłem Europejczyków, którzy za takie brali stowarzyszenia czarowników. Por. E.E. Eva n s-Prit ch ard, Mani, Azande Secret Society, „Sudan Notes and Records" 1931, vol. XIV, s. 105-48; oraz ide m, Czary, wyrocznie i magia u Azande, Warszawa 2008 (Seria Antropologiczna).

7 Przykładem tajnego zwiazku kobiet jest Sande (inaczej: Bundu) w Sierra Leone i Liberii. Por. C.P. Hoffer, Bundu: Political Implications of Female Solidarity in a Secret Society, [w:] Being Female: Reproduction, Power and Change, ed. D. Raphael, Paris 1975, s. 155-164.

8 Stowarzyszeniem, którego jednym $z$ najważniejszych zadań jest tradycyjna edukacja, jest Komo u Bambarów.

9 Przykładem stowarzyszenia, w którym ważna rolę odgrywa kult przodków, jest Poro. 
którzy stanowią ogromną część mieszkańców Afryki Zachodniej. Wierza oni, że zmarli sa nadal obecni w życiu doczesnym, moga wpływać na losy żywych, często w większym stopniu niż przed śmiercią. Przemożnemu przekonaniu, że „zmarli żyja”, daje wyraz senegalski poeta Birago Diop (1906-1989):

Umarli zostaja, nie odchodza nigdy.

Sa $w$ cieniu, który się rozjaśnia,

I w cieniu, który gestnieje $w$ mrok.

Sa $w$ drzewie, które grzmi.

$\mathrm{Sa} w$ drzewie, które jęczy.

Sa $w$ wodzie płynacej.

Sa $w$ wodzie sennej i leniwej.

Sa $w$ chacie $i$ łodzi.

Martwi nie sa martwymi ${ }^{10}$.

W wymiarze kultury materialnej tajne stowarzyszenia sa odpowiedzialne za wykonywanie i przechowywanie artefaktów zwiąanych $z$ religia i obrzędami, w tym masek. $Z$ kultu przodków wynika znaczenie poświęconych zmarłym ceremonii i częste ich odwzorowywanie w sztuce zarówno pod postacia figur, jak i masek. Inne maski mają wzbudzać emocje - chociażby strach lub podziw. Dzięki temu wypełniana może być społeczna rola zwiazku, tzn. przekazywanie wiedzy, zasad obowiązujących w danej grupie lub pilnowania porządku.

Sakralny bądź użytkowy charakter wielu artefaktów nie oznacza jednak, że mieszkańcy Afryki nie odczuwali, czy też nie odczuwaja, potrzeby tworzenia i otaczania się pięknymi przedmiotami, które byłyby również istotnym środkiem wyrazu kulturowego ${ }^{11}$. Trudność w doprecyzowaniu określenia „sztuka” jest jedynie jednym $z$ przykładów na nieprzystawanie terminów stworzonych w świecie Zachodu w badaniach nad kulturami afrykańskimi. Ta nieprzystawalność właśnie w odniesieniu do wytworów wywodzących się z kul-

10 Cyt. za: A. Thiele, Sztuka Afryki, Warszawa 1974, s. 261.

${ }^{11}$ Badacze poszukuja odpowiedzi na pytanie o charakterystyczne cechy sztuki afrykańskiej. Olatunji Alabi Oyeshile uważa, że „sztuka ta jest holistyczna i wielopostaciowa, ma na celu pojednanie Afrykanów $z$ ich otoczeniem. [...] Unikalna cechą sztuki afrykańskiej jest jej wspólnotowa natura. Innymi słowy, sztuka ta ma wymiar społeczny". O.A. Oyes hile, Re-teoretyzowanie rodzimej sztuki i estetyki w rozwoju Afryki - na przykładzie ludu Joruba, [w:] Sztuka Afryki. Afrykańska tradycja-afrykańska nowoczesność, red. A. Pawłowska, J. Sowińska-Heim, Łódź 2016, s. 26. 
tur Zachodu i kultur afrykańskich spowodowała, wraz z wieloma innymi mylnymi lub uproszczonymi wyobrażeniami na temat Afryki i jej mieszkańców, że twórczość Afrykanów przez wieki traktowana była jako mniej cenna pod względem wkładu, jaki wniosła w rozwój cywilizacyjny świata i ludzkiej myśli. Co więcej, postrzegana była nawet tak ekstremalnie, jak przez skojarzenia $z$ perwersja. $\mathrm{W}$ tym kontekście w odniesieniu do odbioru sztuki afrykańskiej w świecie Zachodu, poruszając kwestię tak żywej w imaginarium afrykańskim sfery sacrum, na ciekawe zjawisko zwrócił uwagę współczesny literaturoznawca i historyk sztuki W.J.T. Mitchell. Poddając analizie sposób, w jaki „większość nowoczesnych, oświeconych ludzi” przygląda się tradycyjnym wytworom artystycznym społeczeństw plemiennych, zauważył, że oto: „wydaja się one prymitywne, psychotyczne lub dziecinne (oddawanie czci przedmiotom materialnym; traktowanie przedmiotów nieożywionych, na przykład lalek, jakby były żywe), zaś w nowoczesnych sa to symptomy patologiczne (fetyszyzm towarów lub neurotyczna perwersja)"12.

W związu $z$ tym rodzi się szereg pytań, m.in. czy skoro europejski termin „sztuka” nie był znany większości społeczności afrykańskich, to należy wprowadzać wywodzacy się $z$ tej samej strefy kulturowej podział na sztuki wysokie i rzemiosło artystyczne ${ }^{13}$ ? Dlatego wiele publikacji ze schyłku XX w. proponuje odrzucenie europejskiego konceptu sztuki rozumianej jako dziedzina czystej kontemplacji, w wyniku której powstaja twory nieużyteczne, czyli obiekty tzw. czystej sztuki oraz sztuki dla sztuki (l'art pour l'art $)^{14}$. Zamiast tego należałoby mówić o sztuce rozumianej jako estetyczny wynik każdej ludzkiej działalności. Takie ujęcie problemu proponuje m.in. monografia dotyczaca antropologii sztuki Evelyn P. Hatcher zatytułowana Art As Culture: An Introduction to the Anthropology of Art $^{15}$.

Pomijajac trudny do rozstrzygnięcia problem, gdzie przebiega granica między sztuka a rzemiosłem, należy pamiętać, że w odniesieniu do kultur afrykańskich pominięcie grupy przedmiotów, które można postrzegać jako wytwory rzemiosła, spowoduje wyłączenie

\footnotetext{
${ }^{12}$ W.J.T. Mitche11, Czego chca obrazy, Warszawa 2015, s. 66.

13 Badania skoncentrowane na sztuce i ikonografii Zachodu zazwyczaj nie uwzględniają wytworów rzemiosła.

${ }_{14}$ Szerzej: An Anthology of African Art. The Twentieth Century, eds N. Fall, J. Loup Pivin, New York-Paris 2002, s. 8 i passim.

${ }^{15}$ P. Hatcher Evely n, Cross-Cultural Issues in Art: Frames for Understanding, Westport 1999.
} 
z przedmiotu badań grupy źródeł niezmiernie istotnych. Takimi wytworami sa przykładowo pałacowe drzwi władców Joruba w dzisiejszej Nigerii. Drewniane rzeźbione drzwi, które pełniły określoną funkcję w systemie legitymizacji władzy, dzięki przedstawieniu wydarzeń $z$ historii Jorubów sa źródłami poświadczającymi historię tego ludu. Wysoki kunszt wykonania tych przedmiotów pozwala nie tylko traktować je jako dzieła sztuki, lecz także odczytać ich przekaz ${ }^{16}$. Następnym przykładem, pochodzacym $z$ innego obszaru kulturowego, sa etiopskie krzyże. Wykonywane przez setki lat w różnych materiałach, bogato zdobione, są zarówno świadectwem etiopskiej kultury chrześcijańskiej, jak i zapisem bogatej symboliki związanej $z$ wiarą mieszkańców tego obszaru ${ }^{17}$.

Kolejny problem dotyczacy podejmowanego tematu to niekoherentność przekazu ikonograficznego. Europę bowiem spaja duch prawa rzymskiego i religii chrześcijańskiej, natomiast kultury afrykańskie są bardziej zróżnicowane. Cytując zdanie D. Etounga-Manguelle: „Afrykańska różnorodność może wprawić w oszołomienie nawet najbardziej odpornego człowieka"18. Takie zróżnicowanie, zwłaszcza $z$ często eurocentrycznym nastawieniem obserwatorów, a czasami również badaczy sprawia, że w analizach wytworów afrykańskiej kultury materialnej przenoszone sa doświadczenia świata Zachodu bąź też wiedza o pewnych kulturach afrykańskich na odmienne, odległe kulturowo obszary. Inne, niezmiernie złożone zagadnienie dotyczy akulturacji, a konkretnie próby określenia, w jakim stopniu ikonografia kolonialna (np. motywy chrześcijańskie) lub wpływy innych kultur (np. motywy muzułmańskie) wpłynęły na tradycyjną afrykańską ikonografię.

Nie mniej istotny problem wiąże się $z$ systematyka przedmiotu badań. Wieloletni dyrektor węgierskiego Muzeum Etnograficznego w Budapeszcie Tibor Bodrogi (1924-1986), którego publikacja $z$ lat sześćdziesiątych wieku XX wciąż jest podręcznikiem akademickim dotyczacym sztuki "Czarnej Afryki” ${ }^{19}$ na wielu polskich

16 P.J. I m pera to, Zamki do drzwi Bamana: symbole i ich znaczenia, [w:] Estetyka Afryki. Antologia, red. M. Cymorek, Kraków, s. 171-180.

$17 \mathrm{Na}$ temat krzyży etiopskich pisał m.in. S. Chojnacki, Ethiopian Crosses: A Cultural History and Chronology, New York 2006.

${ }^{18}$ D. Etounga-Manguelle, Czy Afryce potrzebny jest program dostosowania kulturowego?, [w:] Kultura ma znaczenie, red. L.E. Harrison, S.P. Huntington, Poznań 2000, s. 127-128.

19 Taki termin przyjął się i funkcjonuje do dziś w polskiej literaturze przedmiotu, pomimo postulowania przez afrykanistów, aby zastapić go terminem „Afryka Subsaharyjska". 
kierunkach etnologicznych, uważał, że: „Każda grupa etniczna, często nawet każda podgrupa, wyraża się w określonym stylu artystycznym, w obrębie którego rozróżnić można pewne "podstyle" czy mniej lub bardziej odrębne tendencje"20. Liczne współczesne studia afrykańskie podkreślaja, że koncepcja tak jednolitego „Czarnego Kontynentu" to konstrukt myślowy Europejczyków podobny do „orientalizmu", jednakże od lat osiemdziesiątych XX w. wśród myślicieli i naukowców akademickich o afrykańskich korzeniach pojawiła się znacząca grupa badaczy, którzy w duchu idei panafrykanistycznych postrzegaja kulturę i filozofię tego kontynentu jako szczególną, odrębną i swoistą formę myśli indywidualnej, wiary tradycyjnej, praktyk i instytucji społecznych charakterystycznych dla całego kontynentu ${ }^{21}$. Ten rodzaj namysłu nad istnieniem i poznaniem zajmuje się interpretacją świata, odsłania systemy myśli i drogi rozumowania poszczególnych społeczność etnicznych, łączac je w całość dorobku kulturowego właściwego dla regionu. Warto dodać, że takie kompleksowe myślenie o sztuce afrykańskiej jest w znacznej mierze zaprzeczeniem wcześniejszych poszukiwań opartych na strukturalistycznym modelu badań stworzonym przez Claude'a Lévi-Straussa (1908-2009). Poszukiwania strukturalne doprowadziły bowiem do zacieśnienia związków między sztuka a etnografią oraz do sztucznej multiplikacji tzw. stylów afrykańskich, w co uwikłana była praca Bodrogiego, określona ironicznie przez amerykańską badaczkę Sidney Kasfir w 1984 r. jako opisywanie przedmiotów afrykańskich zgodnie ze schematem „jedno plemię, jeden styl” (one tribe, one style) ${ }^{22}$. Być może pewnym rozwiązaniem jest geograficzny porzadek narzucony w publikacji An African Journey Through Its Art ${ }^{23}$ autorstwa Fimy Lifshitz African Journey Through Its Art czy w A History of Art in Africa, której redaktorami sa Monica Blackmun Visony i Robin Poynor ${ }^{24}$.

20 T. Bodrogi, Sztuka Afryki, Wrocław-Budapeszt 1968, s. 19.

${ }^{21}$ P.J. Hountondji, Sur la „Philosophie africaine”, Paris 1976; oraz idem, Comments on Contemporary African Philosophy, „UNESCO Journal Diogenes. Paris" 1970, vol. LXXI, No. 2, s. 120-140.

${ }^{22}$ S.L. Kas fir, One tribe, one style? Paradigms in the historiography of African art, „History in Africa” 1984, vol. XI, s. 163-193.

${ }^{23}$ F. Lifs hitz, An African Journey Through Its Art, Bloomington 2009.

${ }^{24}$ A History of Art in Africa, eds M.B. Visona, R. Poynor et al., New York 2007. 


\section{Kwestia zmian}

Jednym z najważniejszych wyobrażeń o Afryce, które nie pozwala na docenienie jej dorobku cywilizacyjnego, jest wciąż pokutujące wyobrażenie o jej niezmienności. W 1825 r. Georg Wilhelm Friedrich Hegel w swojej Filozofii historii twierdził, że Afryka nie jest „historycznym kontynentem, nie wykazuje ani zmiany, ani rozwoju”, a także, iż „Afrykanie nie są zdolni ani do rozwoju ani nauki” oraz że byli zawsze tacy, jak w świecie jemu współczesnym, czyli w wieku XIX ${ }^{25}$. Co prawda poglądy brytyjskiego historyka Hugh Trevora-Ropera ${ }^{26}$, który twierdził, że nie istnieje historia Afryki, a jedynie historia Europejczyków w Afryce, już wiele dekad temu spotkały się z krytyka ze strony badaczy zajmujących się dziejami Afryki, jednak wyobrażenie afrykańskich kultur jako „tradycyjnych" w znaczeniu istnienia pewnego rdzenia kulturowego, który jest absolutny i jego istota nie ulega zmianom, funkcjonuje - przynajmniej w powszechnym odbiorze - do dziś. Jako obserwatorzy wydarzeń na świecie jesteśmy świadomi globalnych zmian, w tym drastycznych przemian zachodzacych w Afryce. Jednocześnie kolonialne wyobrażenia o afrykańskich kulturach, w tym również o sztuce, wciąż są żywe. I tak, coraz bardziej popularnym turystycznym wyjazdom do Afryki Subsaharyjskiej często towarzyszy kupowanie „sztuki afrykańskiej”, przy czym poszukiwana jest właśnie ta „prawdziwa”, która miała pozostać „niezmieniona”. Taki odbiór Afryki powoduje, że dokonujące się tam zmiany postrzegamy nie jako kontynuacje odwiecznego procesu, analogicznego do tego, jaki zachodził w świecie Zachodu, ale jako drastyczną zmianę, która stworzyła kulturę odmienna od tej „prawdziwej”. Tak też wytwory afrykańskiej sztuki i rzemiosła zbyt łatwo dzielimy na „oryginalne” (w znaczeniu: nieskażonych wpływami) oraz na takie, które tej oryginalności, przede wszystkim przez wpływy innych kultur, zostały pozbawione. To założenie nie pozwala dostrzec bogatej wymiany kulturowej, która w każdym okresie obejmowała całą Afrykę, łącznie $z$ obszarami jeszcze stosunkowo niedawno, patrząc na historię w kategoriach długiego trwania, nieznanymi białemu człowiekowi. Trwajace przez setki lat kontakty w basenie Oceanu Spokojnego

25 G. He ge1, Wykłady z historii filozofii, Warszawa 2002, s. 99-101.

${ }^{26}$ Por. H. Trevor-Ro per, The Past and Present: History and Sociology, „Past and Present" 1969, vol. XLII, s. 3-17. 
na wschodnim wybrzeżu ukształtowały kulturę Suahili, a wpływy z północnej Afryki docierały do Afryki Zachodniej, przynosząc nie tylko islam, lecz także inne elementy kulturowe. Ludy afrykańskie kontaktowały się między soba pokojowo (chociażby dzięki handlowi), lecz także przez wojny i podboje. Wzorce kultury europejskiej dotarły do Afryki Subsaharyjskiej wraz z odkryciami geograficznymi i dzięki nim nawiązanymi pierwszymi kontaktami. Wszystkie te kontakty odgrywały ogromną rolę również w kształtowaniu się kultury materialnej, w tym wytworów sztuki, rzemiosła i architektury. Przedmioty te, o ile przetrwały do dzisiaj, stanowia swoisty zapis historii tej wymiany kulturowej. Adekwatnymi przykładami moga być: kanga - wielokolorowa tkanina noszona przez kobiety, rozprzestrzeniona na całym obszarze Afryki Wschodniej i Centralnej oraz współczesna drewniana rzeźba ludu Makonde. W obydwu przypadkach widoczne sa przenikające się wpływy rdzennej tradycji Czarnej Afryki, islamu oraz współczesnej estetyki.

Podejmując analizę ikonograficznego przekazu współczesnej sztuki afrykańskiej, należy zwrócić uwagę, że sztuka współczesna pojawiła się samoistnie w latach czterdziestych i pięćdziesiątych XX w. w Republice Południowej Afryki wraz z działalnością takich białych artystów, jak Walter Battiss (1906-1982) czy Irma Stern (1894-1966) ${ }^{27}$. Przypadek RPA nie był jednak odosobniony, sztuka współczesna dotarła w tym okresie także do innych części kontynentu. W analogicznym czasie pojawiaja się również przykłady afrykańskich ruchów artystycznych inspirowanych przez białych mentorów i marszandów ${ }^{28}$. Jest to ciekawe zjawisko animowane przez zapaleńców sztuki przybyłych z Europy i Stanów Zjednoczonych - byli oni najczęściej wielkimi miłośnikami sztuki współczesnej, która od początku wieku XX uległa fascynacji tradycyjna plastyka afrykańską ${ }^{29}$. Jeden $z$ najwcześniejszych przykładów działalności białych animatorów szkół dla czarnych twórców to zabiegi Margaret Trowell, która w 1937 r. założyła artystyczna szkołę w Mulago w Ugandzie. Inny znaczący przykład to aktywność Franka

27 Por. A. Pawłows ka, Sztuka i kultura Południowej Afryki. W poszukiwaniu tożsamości artystycznej na tle przekształceń historycznych, Łódź 2013, s. 221-222 i 281-283.

${ }^{28}$ Szerzej o nurtach sztuki afrykańskiej inspirowanych przez Europejczyków: An Anthology of African Art..., s. 152-208.

${ }^{29}$ Szerzej: A. Pawłow ska, Przemiany $w$ tradycyjnej estetyce afrykańskiej i jej relacje z kultura europejska, [w:] Wizje i Re-wizje. Wielka Ksiega Estetyki $w$ Polsce, red. K. Wilkoszewska, Kraków 2007, s. 181-192. 
McEwana (1907-1994) - założyciela tzw. Szkoły i warsztatów artystycznych w Salisbury w Rodezji (dziś Zimbabwe) ${ }^{30}$. Istotną postacią $z$ tego kręgu był też Maurice Alhadeff, który działał w Leopoldville (dziś Kinszasa) w Belgijskim Kongo (dziś Demokratyczna Republika Kongo) i był jednym $z$ twórców Muzeum Sztuki Rodzimej (Musée de Vie Indigene 1953) ${ }^{31}$. Inny to surrealistyczny malarz i żołnierz w jednej osobie - Pierre Romain-Desfosses (1887-1954), który jako żołnierz znalazł się z misją w Kongo i w Elisabethville (dziś Lubumbashi), założył Academie d’Art Populaire, zwaną też Le Hangar (Magazyn). Wykreował tam cały szereg uznanych twórców ludowych, takich jak Mwenze Kibwanga (1925-1999), Pilipili Mulongoy (1914-2007) i Bella Sara (?-1968), zalecając im po prostu, by: „usiąść pod drzewem i malować, co się widzi”32.

Mnożyć można przykłady działalności Europejczyków w Afryce $\mathrm{w}$ okresie kolonialnym i pojawiające się $\mathrm{w}$ wyniku tych działań nowe trendy. Sa wśród nich założona w 1951 r. w Brazzaville przez francuskiego matematyka i malarza amatora Pierre'a Lodsa (1921-1988) szkoła Poto-Poto (Ecole de Peinture de Poto-Poto) oraz nurt malarstwa ekspresyjnego - artystyczna kooperatywa Oshogbo w Nigerii, animowana przez niemieckiego lingwistę i poetę Ulli Beiera (1922-2011) i jego żonę, australijsko-austriacką malarkę Susanne Wenger alias Adunni Olurisa (1915-2009) ${ }^{33}$.

Jeśli rozważania nad ikonografią związana $z$ Afryką rozciągniemy także na ostatnie lata, wówczas zmienność i modyfikacja tradycji staje się jeszcze bardziej widoczna i oczywista. Wielu uznanych twórców sztuki współczesnej ma afrykańskie korzenie. Jest to wynik migracji z Afryki, której podłożem sa przede wszystkim liczne zawirowania polityczne w drugiej połowie XX w., a także

${ }^{30}$ Por. D. Skonieczko, Frank McEwen - ojciec nowoczesnej szkoły rzeźbiarskiej w Zimbabwe, [w:] Toruńskie studia o sztuce orientu. Kultury Afryki w świecie tradycji, przemian i znaczeń, red. A. Nadolska-Styczyńska, Toruń 2009, s. 155-160.

${ }^{31}$ Muzeum Sztuki Rodzimej (Musée de Vie Indigene) zostało założone w 1936 r. przez żonę komisarza Rejonu Marcela Maqueta - Jeanne Tombu. W 1953 r., dzięki staraniom M. Alhadeffa, kolekcja uzyskała własny budynek w gmachu dawnej poczty. A. Ros s, Congo Native Art has U.S. Avocate, „New York Times” 1953, August 22, s. 7.

${ }^{32}$ Africa Remix: Contemporary Art of a Continent, [katalog wystawy], ed. S. Njami, Düsseldorf-London-Paris-Stockholm 2007, s. 234.

${ }^{33} \mathrm{Z}$ tym nurtem wiąże się działalność Mbari Mbayo Club - nigeryjskiego klubu artystycznego przeznaczonego dla afrykańskich twórców. Szerzej: Mbari Mbayo Club, Encyclopædia Britannica Online Academic Edition, http://www.britannica. com/EBchecked/topic/371338/Mbari-Mbayo-Club (dostęp: 21 XI 2012). 
współcześnie - w XXI w. Afrykańscy artyści, jak i inni mieszkańcy tego kontynentu, także opuszczali swoje domy, poszukując lepszego życia na Zachodzie. Inna grupę wśród twórców stanowią ci, którzy urodzili się już poza Afryka, ale pochodzenie i kultura rodziców ma istotne znaczenie w ich dorobku. Artyści ci stawali się przykładem postmodernistycznych twórców globalnych. Wśród nich są El Anatsui, Ibrahim El Salahi, Meschac Gaba, Yinka Shonibare, Sokari Douglas Camp. U wielu artystów, m.in. u Yinki Shonibare czy Sokari Douglasa Campa, problem tożsamości łączy się z poszukiwaniem kulturowej autentyczności ${ }^{34}$. W tym kontekście należy postrzegać wypowiedź Ewenzora i Agulu, którzy pisali, że „[...] między kategoriami tożsamości (pochodzenie etniczne, religia, naród) leży przestrzeń kosmopolitycznej tożsamości afrykańskiej”35.

\section{Oralność i piśmienność w Afryce}

Dla rozważań na temat obrazu i jego znaczenia w badaniach afrykanistycznych ogromnie istotna jest kwestia sposobów przekazywania informacji. Jest to związane $z$ wykorzystaniem jako medium słowa mówionego znacznie częściej niż pisma. Większość kultur afrykańskich bazuje na tradycji ustnej, $z$ niewielkim lub żadnym udziałem kultury piśmiennej. Pismo w Afryce funkcjonowało jako związane $z$ kulturą islamu (m.in. na Wybrzeżu Suahili i w Afryce Zachodniej) oraz z kulturą chrześcijańska (Etiopia). Do czasów współczesnych nigdzie w Afryce Subsaharyjskiej jednak nie odgrywało roli tak samo istotnej, jak w nowożytnej Europie. Kwestia oralności kultur afrykańskich ma znaczenie ze względu na dostępność źródeł. Do drugiej połowy XX w. europejskie podejście do badania historii świata wymagało wykorzystania źródeł pisanych. Dopiero prace Jana Vansiny ${ }^{36}$ uświadomiły możliwość badania historii Afryki na podstawie analizy tradycji ustnej i kultury materialnej. Ograniczona ilość tekstów pisanych powoduje, że w badaniach afrykanistycznych przedstawienia wizualne sa wyjątkowo cenne

${ }^{34}$ D. Tolia-Kelly, A. Morris, Disruptive Aesthetics? Revisiting the „Burden of Representation” in the Art of Chris Ofili and Yinka Shonibare, „Thrid Text” 2004, vol. VIII, s. 154.

${ }^{35}$ Cyt. za: M. Baka-Theis, Postkolonialne hybrydy. Wspótcześni artyści nigeryjscy wobec problemu tożsamości i historii, [w:] Sztuka Afryki. Afrykańska tradycja..., s. 158.

${ }^{36}$ Przykładowo J. Van s in a, Oral Tradition as History, Madison 1965. 
dla poznania zarówno historii kontynentu, jak i kultur jego mieszkańców. Często stanowią one jedyne lub podstawowe źródło wiedzy o istotnych wydarzeniach lub procesach zachodzacych w historii Afryki. Ich wykorzystanie - jak w przypadku i innych rodzajów źródeł - nie jest jednak pozbawione pułapek, $z$ których najbardziej istotne wynikają właśnie $z$ odmiennych kodów kulturowych, które jednocześnie są obiektem badań.

Medium, jakim jest język, jest odpowiedzialne za kształtowanie właściwie wszystkich dziedzin życia: poczynając od sposobu organizacji życia społecznego i sprawowania rządów, po rozwój sztuki i rzemiosła. Wpływa to także na możliwość „czytania” wizualnych przedstawień afrykańskich przez badacza przynależącego do świata Zachodu. Jest ona bowiem obwarowana koniecznością podjęcia próby spojrzenia $z$ innej perspektywy niż ta narzucona przez własna kulturę, a co za tym idzie - koniecznościa poznania kultur afrykańskich. Przykładem na związki między kulturą oralna a przekazem za pomoca obrazu może być spojrzenie na współczesną fotografię nigeryjska postrzegana jako kontynuacja jorubskich pieśni pochwalnych ${ }^{37}$.

Egzemplifikacja działalności artystycznej, której interpretacja w znacznym stopniu wykorzystuje metodologię badań nad przestrzeniami kultury na styku oralności i piśmienności ${ }^{38}$, jest etiopskie malarstwo $\mathrm{w}$ tradycyjnym stylu ${ }^{39}$. Chrześcijaństwo, jako religia związana $z$ władza, zostało przyjęte w Etiopii w IV w., tak więc chrześcijańskie tradycje - w tym także tradycje związane ze sztuką - kształtowały etiopska kulturę przez wiele wieków. Chrześcijaństwo, jako religia Abrahamowa czy też religia Księgi, związane było $z$ ważna kulturowo rola pisma, jednak wiele aspektów kultury etiopskich chrześcijan można - korzystając $z$ pewnego uogólnienia - nazwać afrykańskimi. Do końca wieku XX procent Etiopczyków,

${ }^{37}$ Por. A. Ad e eo, From orality to visuality: Panegyric and Photography in Contemporary Lagos, Nigeria, „Critical Inquiry” 2012, vol. XXXVIII, No. 2, s. 330-361.

${ }^{38}$ Między innymi metodologia ta została zastosowana w: M. Prejs, Oralność i mnemonika: Późny barok $w$ kulturze polskiej, Warszawa 2009. Na temat etiopskiego malarstwa w kontekście piśmienności i oralności por. także H. Rubinkowska-Aniol, The Paintings in St. George Church in Addis Ababa as a Method of Conveying Information about History and Power in 20th-century Ethiopia, „Studies of the Department of African Languages and Cultures" 2015, vol. XLIX, s. 115-141.

${ }^{39}$ Por. H. Rubinkows ka-A niol, Antika-Ethiopian airport art as a construction of tradition [w druku]. 
którzy potrafili czytać i pisać, był znikomy, a współcześnie wedle niektórych danych analfabetyzm sięga $70 \%{ }^{40}$. Siłą rzeczy więc konieczny był i jest przekaz za pomoca mediów inne niż pismo. Należy jednak pamiętać, że pismo ma istotne konotacje w etiopskiej kulturze. Jako związane ze sfera sacrum oraz $z$ władza nobilitowało przekazywana informację. Stąd też częste wykorzystanie pisma w malarstwie etiopskim - zarówno tradycyjnym, jak i współczesnym utrzymanym w tradycyjnym stylu (antika). Historie opowiadane przez obraz wspierane sa pismem, na obrazach zapisywane sa imiona przedstawionych bohaterów, nieraz miejsce wydarzenia lub samo wydarzenie (np. „Bitwa pod Adua” lub „Zmartwychwstanie"). W ten sposób obraz przekazuje informacje, które najczęściej dotycza religii, władzy lub wydarzeń historycznych, a pismo sprawia, że opowiadana historia zyskuje na znaczeniu.

O wadze kulturowej relacji między pismem (reprezentującym $z$ jednej strony rzady kolonialne, ale $z$ drugiej - wielkie religie: islam i chrześcijaństwo) a przekazem oralnym oraz o świadomości tych zależności świadczą także przykłady, które znaleźć można we współczesnej sztuce afrykańskiej. Adekwatnym przykładem, choć przekraczającym obszar Czarnej Afryki ${ }^{41}$, może być tu działalność dwóch tunezyjskich artystów reprezentujących inne pokolenia, dla których motyw pisma jest istotnym elementem twórczości. Nja Mahdaoui (ur. w 1937 r. w Tunisie) nazywa siebie „choreografem liter” i „odkrywca znaków”, a jego prace trafiły do tak znakomitych instytucji, jak British Museum. Tworzy abstrakcyjne kompozycje, w których ważna rolę odgrywają znaki pisma arabskiego, i w ten sposób poszukuje odpowiedzi na pytanie o tożsamość arabskiego artysty i arabskiej kultury we współczesnym świecie ${ }^{42}$. El Seed (ur. 1981) jest o ponad pokolenie młodszym o Nja Mahdouiego urodzonym w Paryżu artystą o tunezyjskich korzeniach. Również w jego pracach pismo odgrywa duże znaczenie, tworzy on bowiem spontaniczne napisy $\mathrm{w}$ formie kaligrafowanych liter na murach w przestrzeni miast Afryki Północnej.

40 Takie dane można znaleźć m.in. na stronie Ambasady Rzeczypospolitej Polskiej w Addis Abebie, http://www.addisabeba.msz.gov.pl/pl/c/MOBILE/wspolpraca _dwustronna/polska_pomoc/informacje/(dostęp: 11 IV 2018).

${ }^{41}$ Autorki uznały, że ze względu na żywą obecność religii i kultury muzułmańskiej w Afryce Subsaharyjskiej (Czarnej), tak wymowne przykłady sa zasadne.

${ }^{42}$ Informacje o artyście na: www.nja-mahdaoui.com/biography/ (dostęp: 18 IV 2018). 


\section{Analizy ikonograficzne wybranych obiektów}

\section{Solniczki z kości słoniowej ludu Sapi z Sierra Leone}

W okresie późnego renesansu, począwszy od schyłku wieku XV, artefaktami chętnie przywożonymi do Europy przez żeglarzy portugalskich były wyroby $z$ kości słoniowej wytwarzane przez lud Sapi (inaczej: Temne) na zachodnim wybrzeżu kontynentu afrykańskiego $^{43}$. Maja one formę ustawionych na postumencie rzeźbionych, kulistych puzderek $\mathrm{z}$ pokrywkami, pustych wewnattrz. Wykonane sa w technice grawerowania. Obiekty maja ok. 20-30 cm wysokości. Wkrótce te przedmioty użytkowe $z$ „białego złota”, jak określano kość słoniowa, stały się cennymi prezentami $z$ dalekich wypraw, często przeznaczone były dla mecenasów portugalskich wojaży. Między innymi podarowane zostały królowi Hiszpanii Karolowi V (1500-1558) ${ }^{44}$. Między rokiem 1520 a 1521 słynny niemiecki malarz i grafik Albrecht Dürer (1471-1528) zakupił dwie takie rzeźby podczas pobytu w Niderlandach. Co więcej, zachwycony jakościa ich wykonania, swoje wrażenia odnotował w dzienniku: „Wszelkiego rodzaju wspaniałe obiekty przeznaczone do użytku przez człowieka można znaleźć o wiele piękniejsze, niż mówi się w baśniach. [...] A przez wszystkie dni mego życia nie widziałem niczego, co radowałoby moje serce jak te rzeczy, gdyż widziałem, że sa niezwykle pomysłowe i zastanawiałem się nad subtelnym geniuszem owych ludzi w dziwnych krajach"45.

Obiekty tego typu stanowią wzór adaptacji rodzimego rzemiosła afrykańskiego pod kątem oczekiwań europejskich odbiorców. Ze względu na swoje walory zarówno estetyczne, jak i wartość surowca były troskliwie przechowywane w kolekcjach w książęcych gabinetach osobliwości, tzw. Kunst- und Wunderkamme ${ }^{46}$.

${ }^{43}$ Por. W. F agg, Afro-Portuguese Ivories, London 1959.

${ }^{44}$ The Idol in the Age of Art. Objects, Devotions and the Early Modern World, eds M. Cole, R.E. Zorach, Burlington 2009, s. 21.

45 Cyt. za: W. Fagg, African Majesty: From Grassland and Forest: The Barbara and Murray Frum Collection, May 22-July 12, 1981. Introduction by Alan G. Wilkinson, Toronto 1981, s. 9 (tłumaczenie Autorek).

${ }^{46}$ Popularny w okresie od XVI w. zwyczaj prezentacji zgromadzonych przedmiotów artystycznych $z$ innych kontynentów obok muszli, piór i kości dinozaurów przetrwał aż do połowy wieku XIX i dał początek muzeom etnograficznym, gdzie znajduje się najwięcej obiektów związanych z kontynentem afrykańskim. Por. A. Pawłows ka, O potrzebie tworzenia kolekcji sztuki afrykańskiej, [w:] Muzeum sztuki. Od Luwru do Bilbao, red. M. Popczyk, Katowice 2006, s. 272-281. 
Solniczki zdobione są zarówno elementami związanym $z$ ikonografią chrześcijańska, np. motywami Madonny z dzieciątkiem, Daniela w jaskini lwa, trojga młodzianów w piecu ognistym oraz królewski herbem Portugalii (solniczka ze zbiorów British Museum w Londynie nr inw. Af1981,35.1.a-b), jak też ornamentami kojarzonymi z tradycyjnymi wzorami afrykańskimi, takimi jak kameleony (solniczka ze zbiorów Seattle Art Museum, Nasli and Alice Heeramaneck Collection, nr inw. 68.31). Wzory często uzupełniane były o przedstawienie portugalskich żołnierzy. Wiele $z$ postaci ukazanych na solniczkach, choć ich strój wskazuje na europejskie konotacje (zbroja, krzyże na łańcuchach), ma negroidalne rysy twarzy.

Powtórne odkrycie owych zapomnianych i źle interpretowanych szesnasto- i siedemnastowiecznych eksponatów sprowadzanych z Afryki nastapiło dopiero w XX stuleciu, dzięki badaniom Williama Fagga i Ezio Bassaniego, które pozwoliły na właściwą identyfikację dzieł $z$ kości słoniowej.

\section{Fetysze ${ }^{47}$ nkondi}

Wiele przykładów afrykańskiej sztuki wskazuje na specyficzne pojmowanie jej natury przez tych wytwarzajacych interesujace nas obiekty. Jest to bowiem sztuka, która przyznaje niski priorytet naśladownictwu zewnętrznego wyglądu, natomiast wysoki priorytet interpretacji niewidzialnej rzeczywistości. Po przykład sięgnać można do kultury materialnej obszaru Demokratycznej Republiki Konga $z$ charakterystycznymi figurami magicznymi, których działanie uznawane jest za potężne. Nazywają się nkisi (1. mn. nkondi), a ich moc wiaże się $z$ magiczno-fetyszystycznym systemem religijnym vodun. Reprezentatywnym przykładem jest drewniana figura postaci ludzkiej o wysokości $116,8 \mathrm{~cm}$, udekorowana muszlami kauri, gwoździami ${ }^{48}$ i piórami (wystawiana w Detroit Institute of Arts,

${ }^{47}$ Nazwa „fetysz” (pochodząca od port. słowa feitiço - „amulet”, „czary”), jakkolwiek kontrowersyjna w środowisku polskich afrykanistów, to jednak bywa obecnie coraz częściej używana, m.in. na wystawie „W służbie władców i czarowników. Sztuka Nigerii" w Muzeum Archeologiczne i Etnograficzne w Łodzi (9 X 2015 - 29 II 2016). Obiekty tego typu były wykonywane przez czarowników-uzdrowicieli. Szerzej np. D. Rush, Ephemerality and the Unfinished in Vodun Aesthetics, „African Arts" 2010, vol. XLIII, No. 1, s. 60-75. Kwestia zasadności używania tego terminu w odniesieniu do kultów Afryki Zachodniej była też podejmowana w trakcie konferencji „Small. Małe. Ukryty świat Afryki”, Kraków 10 V 2016, w wystapieniu J. Lapotta i L. Buchalika Czy Afryka potrzebuje fetyszy?

${ }^{48}$ Prawie w całej Afryce występuja rudy żelaza, a ich wytop jest ściśle związany $z$ rozwojem afrykańskich cywilizacji. Więcej na ten temat: S. Chirikure, Met- 
nr 76.9). Wiara w magiczna moc przedmiotu to koncepcja łączaca na zasadzie dialektycznych sprzeczności pozornie przeciwstawne idee: tego, co ulotne (nietrwałe, przemijające, krótkotrwałe), i tego, co niedokończone (ciagłe, trwałe, niekończace się). Wyznawców vodun cechuje nieustanne, sensualne, aktywne uczestnictwo w obrzędach, podczas których $z$ odbiorców stają się uczestnikami działań magicznych. Dlatego obiekty wytwarzane w związku $z$ tym kultem nigdy nie są całkowicie zakończone, a jedynie wciąż przekształcane i konstruowane od nowa, przez co stają się efemerycznie ulotne. Herbert Cole podkreślał, że ważny jest tu „sam proces [twórczy], a nie forma”, a ponadto, że w sztuce afrykańskiej „większy nacisk jest położony na przemijanie niż na trwałość" ${ }^{\prime 9}$. Zatem proces twórczy nie jest skupiony na „realizacji i izolacji obiektu [...], ale jego rozwoju i stawaniu się" ${ }^{\text {. }}$. Do grupy tych magicznych figur należą obiekty charakterystyczne m.in. dla ludów: Songye, Teke, Vili, Zambo. Taki obiekt kultu ma w rozumieniu afrykańskim siłę magiczną skumulowana $\mathrm{w}$ ingredientach go konstruujacych. Ale jest on także przedmiotem - i jako taki może budzić zainteresowanie badaczy historii sztuki - choć sprowadzenie go jedynie do tej roli powoduje niezrozumienie jego istoty. Konieczne jest także poznanie kontekstu, w jakim funkcjonuje. W przypadku nkondi ma on duży wpływ na społeczność - jest bowiem wzywany do wywoływania uprawnionych skutków, uważa się, że ma własną wolę i może kierować zachowaniem ludzi.

\section{Ibeji - nigeryjskie figurki bliźnią $\mathrm{t}^{51}$}

W Afryce Subsaharyjskiej urodzenie bliźniąt było traktowane jako wydarzenie wymykające się przyjętym zasadom. Same bliźnięta traktowano dwojako - w zależności od zasad panujących w różnych społecznościach. W niektórych społecznościach zabijano je ${ }^{52}$,

als in Past Societies: A Global Perspective on Indigenous African Metallurgyi, Cape Town 2015, s. 116. Gwoździe były także importowane do Afryki z Europy. Szerzej: B. Nowak, Ekspansja europejska $w$ Afryce $w$ XVII-XVIII w., [w:] Historia Afryki do początku XIX wieku, red. M. Tymowski, Wrocław-Warszawa-Kraków 1996, s. $1082-1167$.

${ }^{49}$ H. Cole, Art as Verb in Iboland, „African Art” 1969, vol. III, No. 1, s. 34.

50 Ibidem, s. 41.

${ }^{51} \mathrm{~W}$ literaturze przedmiotu stosowana jest także spolszczona nazwa Ibedżi. Por. M. Baka-Theis, Rzeźby bliźniąt Ibedżi. Forma $i$ styl wybranych regionów Królestwa Joruba (Nigeria), [w:] Kultury Afryki, red. A. Nadolska-Styczyńska, Torun 2009, s. 133-143.

${ }^{52}$ Zabijanie bliźniąt miało na celu uchronienie całej wspólnoty od wszelkich zagrożeń. Por. S. Piła szewicz, Religie Afryki, Warszawa 2000, s. 72, 102. 
uważając ich narodzenie za zły omen. Pojawienie się bliźniąt naruszało bowiem tabu, które zakazywało naśladowania zwierząt, a te wydaja na świat wieloraczki. W innych społecznościach narodziny bliźniąt uważano za znak od bogów i czczono jako święte (m.in. wśród Mende ze Sierra Leone, Baule $z$ Wybrzeża Kości Słoniowej, Lele $z$ Konga). Tradycja tworzenia ibeji (jako pary lub pojedynczych figurek) sięga na obszarze Nigerii połowy XVIII w., gdy pod wpływem kontaktu $z$ Europejczykami zaprzestano zabijać dzieci pochodzace $z$ ciąż mnogich ${ }^{53}$. Tereny zamieszkane przez lud Jorubów to miejsce, gdzie najczęściej (w skali świata) rodzą się bliźnięta, które w wierzeniach tego ludu zajmują obecnie szczególne miejsce. W przypadku śmierci jednego lub obu bliźniąt rodzice zwracaja się do kapłana zwanego babalawo o wyznaczenie rzeźbiarza do wykonania drewnianej figurki (lub figurek) zmarłych. Wyrzeźbione postaci (lub pojedyncza figura) sa umieszczane na ołtarzu domowym, gdzie reprezentuja bóstwo - orisha. Ibeji opiekowała się matka zmarłego dziecka (dzieci), ubierając je, karmiąc i myjąc, co miało zapewnić powodzenie drugiemu bliźniakowi i rodzinie, ale także umożliwić zmarłemu dziecku czynne uczestnictwo w życiu rodziny ${ }^{54}$. Te statuetki stawały się siedzibą duchów zmarłych. Jorubowie wierzyli, że bliźniacy dzielą tę samą duszę i kiedy jedno $z$ nich umiera, dusza drugiego staje się w połowie martwa, a przez to jego życie jest zagrożone. Tradycyjne wierzenia Jorubów łącza idee nieśmiertelności duszy i reinkarnacji $z$ kultem przodków. Matki często nosiły drewniane figury przy sobie, traktując je jak żywe dzieci, figurę nosiło także pozostałe przy życiu bliźnię. W miejscowości Erapo, położonej między Lagos a Badagri, znajdowała się główna świątynia Ibedżi, od wieku XIX miejsce pielgrzymek rodziców bliźniąt ${ }^{55}$.

Figurki ibeji tradycyjnie wykonywane sa za pomoca ciosła lub siekierki $z$ różnych gatunków drewna. Ich wysokość wynosi od $16 \mathrm{~cm}$ do $34 \mathrm{~cm}$ i co ważne, często nawet te przechowywane w kolekcjach muzealnych noszą ślady użytkowania w obrzędach religij-

${ }^{53}$ L. Magesa, African Religion: The Moral Traditions of Abundant Life, New York 1997, s. 147.

${ }^{4}$ Szerzej: L. Segy, The Yoruba Ibeji statue, „Acta Tropica” 1970, vol. XXVII, s. 103. O dwoistości znaczenia figurek Ibeji por. L.M. H arvey, Engaging the Orisa: An Exploration of the Yoruba Concepts of Ibeji and Olokun as Theoretical Principles in Black Theology, „Black Theology: An International Journal” 2008, vol. I, s. 64.

55 Por. M. Baka-Theis, Rzeźby bliźniąt Ibedżi..., s. 139. 
nych, np. sa zanieczyszczone papka z prosa, która były „karmione”. Część figurek pokryta jest barwnikami roślinnymi oraz ozdobiona sznurkami koralików ze szkła piaskowego w kolorze zielonymi i niebieskim. Taki rodzaj ozdób świadczy o wyznawaniu przez matkę dzieci kultu wodnego boga Oszuna.

\section{Dzieło Johna Thomasa Bainesa}

W kolekcji Museum Africa w Johannesburgu pod nr AM 1215 przechowywany jest dzieło Johna Thomasa Bainesa (1820-1875) zatytułowane Bushman's Krantz Baviaans River Animals painted on the rock by the Bushman [sic]. Much visited by the Poet Pringle $(50 \times 63 \mathrm{~cm}), 1849$. Ten niewielkich rozmiarów olejny obraz skupia niczym w soczewce liczne wątki charakterystyczne dla Afryki Południowej, afrykańskiego obszaru od połowy XVII w. systematycznie zasiedlanego przez białych kolonizatorów. Silna i wielowiekowa infiltracja terenów przez osadników europejskich znacząco wpłynęła na sztukę i kulturę wszystkich żyjących tam grup. Przywołany obraz jest dziełem profesjonalnego angielskiego artysty - towarzysza wypraw słynnego podróżnika Davida Livingstona. Baines w połowie wieku XIX był ważnym członkiem kapsztadzkiej elity intelektualnej. $\mathrm{Na}$ omawianym obrazie artysta przedstawił grotę znajdującą w Prowincji Przylądkowej Wschodniej $z$ malunkami ludu San, wówczas określanego jako Buszmeni - autochtonów zamieszkujących Afrykę Południową. Powyżej fryzu znajduje się inskrypcja „T. Pringle 1825” - wyryta przez Thomasa Pringle'a (1789-1834), pierwszego anglojęzycznego poetę Afryki Południowej. Scenę uzupełniają siedzący na pierwszym planie artysta zajęty szkicowaniem oraz śpiąca męska postać (bratanek poety?). Należy podkreślić, że przywołany w tytule obrazu poeta Pringle w przeciwieństwie do większości kolonizatorów był pozytywnie nastawiony do rdzennych mieszkańców Kolonii Przylądkowej i jako pierwszy zwrócił uwagę na malowidła tworzone przez lud San. Ćwierć wieku później, w 1849 r., bratanek poety, Robert, zaprezentował owe malatury Bainesowi (1820-1875) ${ }^{56}$, który uwiecznił grotę $z$ rysunkami naskalnymi.

Na swoim obrazie Baines ukazał kompletne imaginarium kultury ludu San zaprezentowane na fryzie w grocie. Sa tu różne gatunki

56 S. Ouzman, Graffiti as artefact: a contemporary archaeology. Seminar paper presented to Department of Sociology, „Anthropology \& Development Studies” 2010, March 10, University of Johannesburg, s. 11-15. 
antylop (elandy, antylopy krowie, kudu), nosorożce, żyrafy, postacie ludzkie oraz trudne do zidentyfikowania stworzenia i "groteskowe przedstawienia mężczyzn zaangażowanych w pościg lub wojny", jak opisywał je sam artysta ${ }^{57}$. Baines zadał sobie także dużo trudu, aby uzyskać informacje na temat techniki malarskiej stosowanej przez lud San. Według „starego hotentockiego"58 informatora - to znów wzmianka $z$ pamiętnika malarza - pigmenty zastosowane we fryzie były uzyskiwane „z czerwonych, żółtych i białych glinek oraz węgla drzewnego, zmieszanych $z$ tłuszczem, który to barwnik, połączony palącym słońcem, stawał się nieusuwalny". Ponadto malunki były wykonane bez „najmniejszych prób modelunku światłocieniowego, wymieszania barw lub zastosowania perspektywy [geometrycznej - przyp. A.P.], z elementami w różnych rozmiarach" ${ }^{59}$. Dociekliwość malarza naturalisty wynikała $z$ pobudek czysto naukowych, bo choć nie doceniał fryzu, to jednak czuł, że jego obowiązkiem jest przekazać wiedzę o nim możliwie jak najwierniej.

$Z$ obecnej perspektywy można uznać, że praca malarza jest wytworem typowym dla wiktoriańskiego światopoglądu i zawiera w postaci mniej lub bardziej zawoalowanej dowody nieustajaccego brytyjskiego postępu społeczno-gospodarczego oraz prezentuje pozytywną siłę wartości imperialnych. Twórczość artysty wyraźnie służy osadzeniu niezwykle modnych w XIX w. opowieści prezentowanych w książkach podróżniczych w konkretnych realiach geograficzno-przyrodniczych. Malarstwo to jednocześnie plastycznie unaocznia zapisy prowadzone w dzienniku przez Bainesa i potwierdza szczególne interpretacje historii, stosowane do uwierzytelniania „rzeczywistości”60. Oczywiście, zgodnie $z$ duchem dziewiętnastowiecznego kolonializmu brytyjskiego, „rzeczywistość” powinna jasno ukazywać zwycięski charakter ekspansji terytorialnej, dlatego też ponad fryzem autochtonów $z$ malowniczej groty nad rzeka Baviaans dumnie prezentuje się monogram Pringle'a. $Z$ tego samego powodu Baines do sceny wprowadził także własną postać w trakcie szkicowania obrazu.

${ }^{57}$ Journal of residence in Africa 1842-1853, by Thomas Baines, vol. II (18501853), ed. R.F. Kennedy, Cape Town 1964, s. 116.

58 Hotentotami nazywano wówczas lud Khoi.

59 Ibidem.

60 J. Carruthers, M. Arnold, The life and work of Thomas Baines, Vlaeberg 1995, s. 14. 


\section{Wnioski}

$\mathrm{W}$ artykule tym autorki pokusiły się jedynie o zaznaczenie problematyki, zbyt szerokiej, by ramy tego tekstu pozwoliły na wyczerpanie tematu. Nie tylko kultury afrykańskie są bardzo różnorodne, ogromnie zróżnicowane są też przedstawienia wizualne pochodzące $z$ tych kultur. Podkreślenie tej różnorodności było jednym $z$ celów publikacji. Każde $z$ przedstawień, przynajmniej w drobnej części, jest wynikiem procesów przebiegających na kontynencie, wpływów $z$ innych części świata, migracji ludzi i idei, zderzania się religii i przenikania języków, a także po wielokroć zmieniających się kontekstów, w jakich funkcjonowały i funkcjonuja te przedstawienia. Do końca XIX w. wiedza ludzi Zachodu o interiorze afrykańskim była niewielka. Do dzisiaj wiedza na temat kulturowego dorobku Afryki jest często skażona stereotypami i wyobrażeniami mającymi korzenie w czasach kolonialnych, a być może i wcześniejszych doświadczeniach. Innymi słowy, jako odbiorcy upraszczamy obrazy tworzone przez Afrykanów. Tymczasem to te obrazy właśnie moga służyć jako narzędzie do lepszego poznania tej części świata i kultur wypracowanych przez jej mieszkańców. Tym bardziej że kultury afrykańskie coraz częściej i w większym stopniu przenikaja do świata Zachodu.

Przykłady przytoczone $\mathrm{w}$ artykule pochodzą $z$ różnych obszarów kulturowych i wskazuja na odmienne problemy zwiazane $z$ analizą wizualnej strony wytworów afrykańskiej kultury materialnej w badaniach afrykanistycznych. W zamierzeniu autorek maja one wskazać, jak różnorodna jest twórczość Afrykanów i jak wiele elementów składa się na informację, którą dzieła te przekazują. Ponadto jak wiele elementów, które nie sa stricte częścią analizowanych obiektów, należy uwzględnić podczas odczytywania obrazu czy też przekazywanej przez niego informacji. Wydaje się, że spojrzenie szersze niż jedynie przez pryzmat odrębnych dziedzin i ich metodologii, tj. historyka sztuki, etnologa czy historyka, pozwala dostrzec zachodzące na siebie obszary znaczeń stanowiące istotę kultur w ogóle, a kultur afrykańskich w szczególności. Badacz, który podejmuje się interpretacji afrykańskiej ikonografii, pracuje $z$ materiałem ogromnie różnorodnym, a jednocześnie wymykającym się systematyzacji wprowadzonej przez europejskich badaczy. Kolejnym utrudnieniem jest to, że niemożliwe jest całkowite odrzucenie własnych schematów kulturowych, a przez to również narzę- 
dzi, którymi posługują się wykształceni na Zachodzie afrykaniści. Nie zmienia to jednak faktu, że omawiany materiał, czyli dorobek afrykańskiej kultury materialnej, pozostaje jednym $z$ najważniejszych mediów, który przekazuje informacje o historii i kulturach tego kontynentu.

\section{Bibliografia}

\section{$\dot{Z}_{\text {RÓDEA DRUKOWANE }}$}

Africa Remix: Contemporary Art of a Continent, [katalog wystawy], ed. S. Njami, Düsseldorf-London-Paris-Stockholm 2007.

Evans-Pritchard E.E., Czary, wyrocznie i magia u Azande, Warszawa 2008.

Evans-Pritchard E.E., Mani, Azande Secret Society, „Sudan Notes and Records” 1931, vol. XIV, s. 105-48.

Fagg W., African Majesty: From Grassland and Forest: The Barbara and Murray Frum Collection, May 22-July 12, 1981. Introduction by Alan G. Wilkinson, Toronto 1981.

Fitzgerald Marriott H.P., The Secret Societies of West Africa, „The Journal of the Anthropological Institute of Great Britain and Ireland" 1899, vol. XXIX, No. $1 / 2$, s. 21-27.

Imperato P.J., Zamki do drzwi Bamana: symbole $i$ ich znaczenia, [w:] Estetyka Afryki. Antologia, red. M Cymorek, Kraków 2008, s. 171-180.

\section{OpRacowania}

A History of Art in Africa, eds M.B. Visona, R. Poynor et al., New York 2007.

Adeeo A., From orality to visuality: Panegyric and Photography in Contemporary Lagos, Nigeria, „Critical Inquiry” 2012, vol. XXXVIII, No. 2, s. 330-361.

An Anthology of African Art. The Twentieth Century, eds N. Fall, J. Loup Pivin, New York-Paris 2002.

Baka-Theis M., Postkolonialne hybrydy. Wspótcześni artyści nigeryjscy wobec problemu tożsamości i historii, [w:] Afrykańska tradycja - afrykańska nowoczesność, red. A. Pawłowska, J. Sowińska-Heim, Łódź 2016, s. 151-173.

Baka-Theis M., Rzeźby bliźniąt Ibedżi. Forma i styl wybranych regionów Królestwa Joruba (Nigeria), [w:] Kultury Afryki, red. A. Nadolska-Styczyńska, Torun 2009, s. 133-143.

Bodrogi T., Sztuka Afryki, Wrocław-Budapeszt 1968.

Burke P., Naoczność. Materiały wizualne jako świadectwa historyczne, Kraków 2012.

Carruthers J., Arnold M., The life and work of Thomas Baines, Vlaeberg 1995.

Chirikure S., Metals in Past Societies: A Global Perspective on Indigenous African Metallurgyi, Cape Town 2015.

Chojnacki S., Ethiopian Crosses: A Cultural History and Chronology, New York 2006. 
Cole H., Art as Verb in Iboland, „African Art” 1969, vol. III, No. 1, s. 34-41, 88.

Etounga-Manguelle D., Czy Afryce potrzebny jest program dostosowania kulturowego?, [w:] Kultura ma znaczenie, red. L.E. Harrison, S.P. Huntington, Poznań 2000, s. 127-143.

Fagg W., Afro-Portuguese Ivories, London 1959.

Harvey L.M., Engaging the Orisa: An Exploration of the Yoruba Concepts of Ibeji and Olokun as Theoretical Principles in Black Theology, „Black Theology: An International Journal" 2008, No. 1, s. 61-82.

Hatcher Evelyn P., Cross-Cultural Issues in Art: Frames for Understanding, Westport 1999.

Hegel G., Wykłady z historii filozofii, Warszawa 2002, s. 99-101.

Historia Afryki do początku XIX wieku, red. M. Tymowski, Wrocław 1996.

Hoffer C.P., Bundu: Political Implications of Female Solidarity in a Secret Society, [w:] Being Female: Reproduction, Power and Change, ed. D. Raphael, Paris 1975 , s. $155-164$.

Hountondji P.J., Comments on Contemporary African Philosophy, „UNESCO Journal Diogenes. Paris" 1970, vol. LXXI, No. 2, s. 120-140.

Hountondji P.J., Sur la „Philosophie africaine”, Paris 1976.

Journal of residence in Africa 1842-1853, by Thomas Baines, vol. II (1850-1853), ed. R.F Kennedy, Cape Town 1964.

Kasfir S.L., One tribe, one style? Paradigms in the historiography of African art, „History in Africa” 1984, vol. XI, s. 163-193.

Lifshitz F., An African Journey Through Its Art, Bloomington 2009.

Magesa L., African Religion: The Moral Traditions of Abundant Life, New York 1997.

Mbari Mbayo Club, Encyclopædia Britannica Online Academic Edition. http://www.bri tannica.com/EBchecked/topic/371338/Mbari-Mbayo-Club (dostęp: 21 XI 2012).

Mitchell W.J.T., Czego chca obrazy, Warszawa 2015.

Nowak B., Ekspansja europejska $w$ Afryce $w$ XVII-XVIII w., [w:] Historia Afryki do poczatku XIX wieku, red. M. Tymowski, Wrocaw-Warszawa-Kraków 1996, s. $1082-1167$.

Ouzman S., Graffiti as artefact: a contemporary archaeology. Seminar paper presented to Department of Sociology, „Anthropology \& Development Studies” 2010, March 10, University of Johannesburg, s. 11-15.

Oyeshile O.A., Re-teoretyzowanie rodzimej sztuki i estetyki w rozwoju Afryki-na przykładzie ludu Joruba, [w:] Sztuka Afryki. Afrykańska tradycja-afrykańska nowoczesność, red. A. Pawłowska, J. Sowińska-Heim, Łódź 2016, s. 20-38.

Panofsky E., Studia z historii sztuki, oprac. J. Białostocki, Warszawa 1971.

Pawłowska A., O potrzebie tworzenia kolekcji sztuki afrykańskiej, [w:] Muzeum sztuki. Od Luwru do Bilbao, red. M. Popczyk, Katowice 2006, s. 272-281.

Pawłowska A., Przemiany $w$ tradycyjnej estetyce afrykańskiej i jej relacje $z$ kultura europejska, [w:] Wizje i Re-wizje. Wielka Ksiegga Estetyki w Polsce, red. K. Wilkoszewska, Kraków 2007, s. 181-192. 
Pawłowska A., Sztuka i kultura Południowej Afryki. W poszukiwaniu tożsamości artystycznej na tle przekształceń historycznych, Łódź 2013.

Piłaszewicz S., Religie Afryki, Warszawa 2000.

Ross A., Congo Native Art has U.S. Avocate, „New York Times” 1953, Aug. 22, s. 7.

Rubinkowska-Anioł H., Antika - Ethiopian airport art as a construction of tradition [w druku].

Rubinkowska-Anioł H., The Paintings in St. George Church in Addis Ababa as a Method of Conveying Information about History and Power in $20^{\text {th }}$-century Ethiopia, „Studies of the Department of African Languages and Cultures” 2015, vol. XLIX, s. 115-141.

Segy L., The Yoruba Ibeji statue, „Acta Tropica” 1970, vol. XXVII, s. 97-145.

Skonieczko D., Frank McEwen - ojciec nowoczesnej szkoły rzeźbiarskiej w Zimbabwe, [w:] Toruńskie studia o sztuce orientu. Kultury Afryki w świecie tradycji, przemian i znaczeń, red. A. Nadolska-Styczyńska, Toruń 2009, s. 155-160.

The Idol in the Age of Art. Objects, Devotions and the Early Modern World, eds M. Cole, R.E. Zorach, Burlington 2009.

Thiele A., Sztuka Afryki, Warszawa 1974.

Tolia-Kelly D., Morris A., Disruptive Aesthetics? Revisiting the "Burden of Representation” in the Art of Chris Ofili and Yinka Shonibare, "Thrid Text” 2004, vol. VIII, s. 153-167.

Trevor-Roper H., The Past and Present: History and Sociology „Past and Present” 1969, vol. XLII, s. 3-17.

Tymowski M., Europejczycy i Afrykanie: Wzajemne odkrycia i pierwsze kontakty, Toruń 2017.

Vansina J., Oral Tradition as History, Madison 1965.

Aneta Paweowska, Hanna Rubinkowska-Anioe

\section{Iconographic sources of African studies. An outline of the problem}

The aim of this article is to consider whether it is possible to support the
research concerning the history and culture of Sub-Saharan Africa through
an analysis of the iconographic sources associated with this continent. The most
important reason for such an attempt is the fundamental lack of any written
documents in the traditional African culture. Second equally substantial part
of the analyzes presented in this article is aimed to draw attention to the diversity
of visual representations derived from this geographical territory. Another reason
for exploring the iconography of this continent is to make an effort to broaden
the reception of the African culture, and especially to attempt to abandon the
Eurocentric ways of describing the world.

Keywords: Africa, culture, iconography, visual arts, history. 